Original Article

\title{
Sniff Nasal Inspiratory Pressure Does Not Decrease in Elderly Subjects
}

\author{
Chien-Hui Huang, PhD ${ }^{1)^{*}}$, Gee-Gwo Yang, MD²), Tung-Wei Chen, MS ${ }^{3)}$ \\ 1) Department of Physical Therapy, Tzu Chi University: No. 701 Zhongyang Rd., Sec 3, Hualien 97004, \\ Taiwan \\ 2) Department of Pulmonary Medicine, Tzu Chi Medical Center, Taiwan \\ 3) Physical Education Office, National Taipei University of Technology, Taiwan
}

\begin{abstract}
Purpose] Measurements of inspiratory strength are critical for detecting inspiratory muscle weakness. Sniff nasal inspiratory pressure (SNIP) is a quick, noninvasive measurement of global inspiratory strength; however, it is not clear how many trials are needed for reliable measurements. [Subjects and Methods] One hundred and nineteen subjects (age 39.9 \pm 16.5 , range 18-69 yrs) completed the study. They were divided into subgroups of different ages and gender. Subjects were asked to take 20 maximal sniffs after normal expiration, with 30 seconds rest in-between. The highest values among the first 10 and last 10 SNIP maneuvers were recorded as SNIP1-10, and SNIP11-20, respectively. The paired t-test was used to compare the differences. Two-way measures ANOVA was used to compare the effects of age and gender on SNIP. [Results] SNIP 11-20 was significantly greater than SNIP1-10, suggesting that 10 trials is not enough to eliminate learning effects. Age did not affect SNIP in either gender, suggesting SNIP is preserved. In stepwise multiple linear regression analysis, the SNIP values were positively related with body mass index in women and positively related with weight in men. [Conclusion] The results suggest that twenty trials are needed for reliable SNIP measurements. The mean value and lower limits of normal SNIP are provided for clinical comparison.

Key words: Respiratory muscle strength, Sniff pressure, Ethnicity
\end{abstract}

(This article was submitted Feb. 27, 2014, and was accepted Apr. 26, 2014)

\section{INTRODUCTION}

The full importance of inspiratory strength may not be widely recognized. It is well known that impaired respiratory muscle strength can lead to pulmonary dysfunction ${ }^{1)}$. Inspiratory muscle weakness is also an independent risk factor for myocardial infarction and cardiovascular disease death $^{2}$. However, as a recent study demonstrated, the association of extremity muscle strength with mortality is not significant when a term for respiratory strength is included $^{3}$. Sniff nasal inspiratory pressure (SNIP) is a noninvasive method of measuring inspiratory muscle strength. SNIP consists of a short maximal sniff through one nostril, and the nostril pressure is measured using a plug occluding the contralateral nostril. SNIP has been suggested as an alternative $^{4)}$ and compliment ${ }^{5)}$ to maximal inspiratory pressure (MIP) measurement.

MIP measures mouth pressure during a maximal inspiratory effort against a quasi occlusion, and it largely dependent on the subject's understanding and precise execution

*Corresponding author. Chien-Hui Huang (E-mail:

chienhuang@mail.tcu.edu.tw)

(C) The Society of Physical Therapy Science. Published by IPEC Inc.

This is an open-access article distributed under the terms of the Creative Commons Attribution Non-Commercial No Derivatives (by-ncnd) License $<$ http://creativecommons.org/licenses/by-nc-nd/3.0/> . of the procedure. In contrast, SNIP is easy to perform and has been used clinically ${ }^{5)}$. SNIP is also more reproducible than MIP $^{6}$. However, SNIP has been very little studied in Taiwan, and the published normal values are only those of Caucasians. The reference value for Caucasians may not be suitable for Taiwanese as previous research has confirmed there are ethnic differences in respiratory strength ${ }^{7}$. Thus, the primary aim of this study was to investigate the SNIP of healthy Taiwanese subjects. The optimal number of multiple tests of SNIP, as well as the mean values and lower limits of the normal values of SNIP were also analyzed.

\section{SUBJECTS AND METHODS}

One hundred and nineteen healthy volunteers (58 men and 61 women), aged 18-69 years, were recruited for this study. The recruitment process was through email announcement and personal invitation to attend a test of "breathing strength for healthy people" at a university campus. All the subjects were students, faculty or staff members, or school volunteers. Smoking has been found to affect SNIP), so smoking status was surveyed. All subjects were non-smokers at the time they took part in the study. Four subjects were ex-smokers, but had not smoked for at least 10 years. The other subjects had never smoked. The exclusion criteria included presence of pulmonary disease, heart disease, neuromuscular disease, cardiovascular disease or pregnancy. In addition, at the time of the experiment, none 
of the subjects had symptoms of respiratory disease, i.e. rhinitis or upper airway infections. The researchers personally confirmed the exclusion criteria with each subject before the study began. The study received Institutional Review Board (IRB) ethical approval. Informed consent to participation in this study was received from each subject.

Weight and height were measured, and the body mass index (BMI) was calculated. Body composition was assessed by bioelectrical impedance (Biospace Inbody 3.0 Body Composition Analyzer, Singapore) to determine body fat $\%$. After taking the above measurements, the researchers took the SNIP measurements.

Our SNIP measurements followed the recommendations of the ATS/ERS Statement on Respiratory Muscle Testing ${ }^{4}$. The subjects watched a video which explained each step of the SNIP measurement procedure in slow motion ${ }^{9}$. Tests were conducted in a single session with the subjects seated. SNIP was measured through a plug occluding one nostril during maximal sniff through the contralateral nostril. The contralateral nostril was not occluded during sniffing. The plug was a plastic probe (4 different sizes) which was connected to a catheter. The end of the catheter was connected to a hand-held pressure meter displaying peak pressure (RPM, Micro Medical, Cardinal Health, Basingstoke, UK). The plug was sterilized after use. The subjects were instructed to take a short, sharp, maximal sniff with the mouth closed at the end of their normal expiration. In order to adjust and fit the size of the probe to each subjects' nostril, each subject took several practice sniffs. During these practice sniffs, we made sure that the probe fitted well, and the subjects familiarized themselves with the technique. Twenty maximal sniffs were then performed by each subject with 30 seconds rest between each sniff. All maneuvers were recorded for later analysis. The highest values among the first 10, and second 10 SNIP maneuvers were recorded as SNIP1-10 and SNIP11-20, respectively.

Descriptive data are expressed as means \pm SD. The paired t-test was used to compare the differences between SNIP1-10 and SNIP11-20. Two-way ANOVA was used to compare the effect of age and gender on the best SNIP value. Stepwise multiple linear regression analysis was performed to assess the contributions of age, height, weight, BMI, and body fat $\%$ to the mean values of SNIP by gender. The lower limits of normal were defined by subtracting 1.64 times the residual SD from the predicted value in the regression mode ${ }^{10)}$. All statistical analyses were performed using SPSS software (SPSS 15.0, SPSS Inc., USA), and sig- nificance was accepted for values of $\mathrm{p}<0.05$.

\section{RESULTS}

The analysis was based on the measurements of 119 healthy subjects (Table 1), average age $39.9 \pm 16.5$ (means \pm SD), and range 18-69 yrs. Subjects were divided into 6 groups according to their age.

No adverse event related to the measurement of SNIP was reported. The pair t-test showed there was a significant difference between SNIP1-10 and SNIP11-20 $(\mathrm{p}<0.05)$, and SNIP11-20 was significantly higher than SNIP1-10 (Fig.1). This indicates that subjects were not able to fully master the skill or perform to their best in the first 10 trials of sniffs. SNIP11-20 is presented as subjects' best SNIP.

Two-way ANOVA was used to compare the effects of age and gender on SNIP11-20. We found that there were no significant differences in SNIP11-20 among the age groups in either gender, suggesting age does not affect SNIP. As expected, SNIP of males was higher than that of females in all age groups. The SNIP data of females and males of different age groups are presented as mean \pm SD and the $95 \%$ Confidence Interval in Table 2.

Multiple regression analysis was used to test if anthropological traits significantly predicted the values of SNIP1120. The results of the regression for females indicate two predictors, BMI and body fat $\%$, explained $18.1 \%$ of the result $\left(\mathrm{R}^{2}=0.18, \mathrm{~F}(2,54)=5.76, \mathrm{p}<0.01\right)$. We found that BMI significantly predicted SNIP11-20 (beta $=2.72, \mathrm{p}<0.01$ ), and body fat $\%$ (beta $=-2.24, \mathrm{p}<0.05)$.

For men, weight explained $16.0 \%$ of the result $\left(\mathrm{R}^{2}=0.16\right.$,

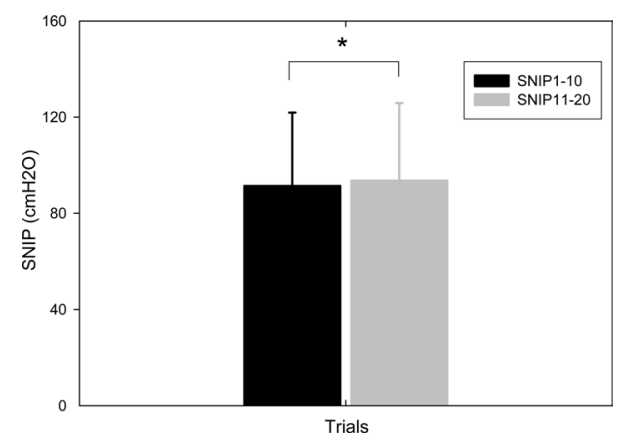

Fig. 1. SNIP1-10 and SNIP11-20 in subjects *, $\mathrm{p}<0.05$

Table 1. The basic characteristics of participants by gender

\begin{tabular}{lccc}
\hline & Female & Male & Total \\
\hline $\mathrm{N}$ & 61 & 58 & 119 \\
Age $(\mathrm{yrs})$ & $40.1 \pm 16.2(18-67)$ & $39.6 \pm 17.0(19-69)$ & $39.9 \pm 16.5(18-69)$ \\
Height $(\mathrm{cm})$ & $154.8 \pm 14.5(143.0-170.0)$ & $172.0 \pm 6.2(160.0-185.0)^{* *}$ & $163.2 \pm 14.1(143.0-185.0)$ \\
Weight $(\mathrm{kg})$ & $54.7 \pm 9.7(38.4-84.6)$ & $72.1 \pm 1.7(52.0-112.0)^{* *}$ & $63.2 \pm 13.4(38.4-112.0)$ \\
Fat percentage (\%) & $30.7 \pm 14.5(17.0-45.0)$ & $22.9 \pm 5.3(10.5-37.0)^{* *}$ & $26.7 \pm 11.5(10.5-45.0)$ \\
BMI $\left(\mathrm{kg} / \mathrm{cm}^{2}\right)$ & $22.9 \pm 6.1(17.5-33.9)$ & $24.4 \pm 3.3(17.2-36.9)$ & $23.6 \pm 5.0(17.2-36.9)$ \\
\hline
\end{tabular}

Data are shown as means \pm SD (Range), ${ }^{* *}<<0.01$, Significantly differently from females 
$\mathrm{F}(1,56)=10.63, \mathrm{p}<0.01)$, and weight significantly predicted SNIP11-20 (beta=3.26, $\mathrm{p}<0.01$ ).

The lower limits of normal of SNIP were determined using the predicted value and the residual SD of the regression model. The residual SD was 20.62 for females and 30.59 for males; thus, the mean lower limits of normal of the predicted SNIP were $52.07 \mathrm{cmH}_{2} \mathrm{O}$ for females and $60.33 \mathrm{cmH}_{2} \mathrm{O}$ for males (Table 3 ).

\section{DISCUSSION}

The main findings of this study were: (1) There was persistent improvement after the tenth sniff meaning that subjects achieved higher SNIP values in 20 trials than in 10 or 15 trials. (2) The SNIP values were positively related with BMI and negatively related with body fat $\%$ in women, and positively related with weight in men. The lower limits of normal for SNIP were $52.07 \mathrm{cmH}_{2} \mathrm{O}$ for females and 60.33 $\mathrm{cmH}_{2} \mathrm{O}$ for males. (3) There was no age difference in SNIP in either gender in the age range studied (18-69 yrs).

According to the ATS/ERS statement of Respiratory Muscle Testing regarding the sniff test ${ }^{4}$ ), "Most subjects achieve a plateau of pressure values within 5-10 attempts". Among published SNIP studies, the adopted numbers of sniff measurements range from as low as $5^{11,12)}$ to as high as $40^{13)}$, with most of them being $10^{14,15)}$. Lofaso et al. ${ }^{13)}$ measured 40 sniffs and found that the best SNIP of the first 10 sniffs was lower than the best SNIP among the next 10 sniffs of healthy subjects. They concluded that a learning effect persists after the tenth sniff and suggested using another 10 additional sniffs when the best result of the first
10 sniffs is below normal. Our present study compared the highest of the first 10, and the second 10 SNIP maneuvers and found significant differences between them. According to our results, the common recommendation of 10 sniffs is insufficient for measuring the best SNIP, and will lead to underestimation. Underestimation of SNIP would not be harmful for the patient, but when the purpose of the SNIP assessment is to evaluate the efficacy of treatment, underestimation of SNIP would subsequently make it difficult to determine whether the SNIP value reflects the effect of the treatment itself or a learning effect. A recent study showed why it is important to make this distinction Bauer et al. ${ }^{16)}$ compared the SNIP of patients with Amyotrophic Lateral Sclerosis (ALS) over 5 months, and found a delayed decline in SNIP when compared to other outcome measurements in phase III of the clinical trial. They suspected that a between-session learning effect in SNIP exists, and when other outcome measurements deteriorated as the disease progressed, SNIP did not. In our opinion, this is probably due to the fact that the optimal number of SNIP measurements for ALS was not performed in the pretest measurement; in other words, the pretest SNIP value was probably underestimated.

Additional analysis indicated that age was not a factor in the optimal trial number. One review paper suggested 20 sniffs for the SNIP measurement of children ${ }^{17)}$. Since the current study covered a wide age range from $18-69$, we recommend 20 sniffs for measurements of SNIP of adults under 69 to allow the full learning effect to materialize.

The ease of SNIP measurement can extend the use of respiratory muscle assessment. It is possible that the mea-

Table 2. The highest SNIP in the first 10 and the second 10 sniffs (SNIP1-10 and SNIP11-20) of each age/gender group

\begin{tabular}{|c|c|c|c|c|c|c|}
\hline & \multicolumn{3}{|c|}{ Female } & \multicolumn{3}{|c|}{ Male } \\
\hline $\begin{array}{l}\text { Age } \\
\text { groups }\end{array}$ & $\mathrm{n}$ & SNIP1-10 & SNIP11-20 & $\mathrm{n}$ & SNIP1-10 & SNIP11-20 \\
\hline $18-20$ & 10 & $78.8 \pm 15.1(68.0-89.6)$ & $80.4 \pm 16.7(68.3-92.4)$ & 10 & $107.0 \pm 40.7(77.9-136.1)$ & $110.0 \pm 42.1(80.2-140.6)$ \\
\hline $21-30$ & 10 & $79.1 \pm 15.1(67.3-89.7)$ & $80.9 \pm 17.7(68.2-93.6)$ & 10 & $99.7 \pm 31.6(77.1-122.3)$ & $99.1 \pm 20.0(79.1-119.1)$ \\
\hline $31-40$ & 11 & $80.9 \pm 12.1(70.3-81.1)$ & $77.9 \pm 10.8(70.7-85.1)$ & 10 & $114.0 \pm 31.1(91.8-136.2)$ & $117.5 \pm 23.9(93.6-141.4)$ \\
\hline $41-50$ & 10 & $78.6 \pm 19.6(72.6-98.7)$ & $93.5 \pm 23.9(76.4-110.6)$ & 9 & $109.2 \pm 15.7(97.2-121.3)$ & $106.9 \pm 24.3(88.2-125.6)$ \\
\hline $51-60$ & 10 & $79.1 \pm 35.4(53.8-104.4)$ & $82.5 \pm 39.4(54.3-110.7)$ & 10 & $98.2 \pm 30.4(76.5-119.9)$ & $102.0 \pm 30.7(80.1-123.9)$ \\
\hline $61-70$ & 10 & $72.6 \pm 31.4(50.1-95.1)$ & $75.2 \pm 32.9(51.6-78.8)$ & 9 & $103.0 \pm 41.7(70.9-135.1)$ & $101.1 \pm 48.1(64.2-138.0)$ \\
\hline Total & 61 & $78.2 \pm 22.2(72.7-84.1)$ & $81.7 \pm 16.8(75.3-88.1)$ & 58 & $105.2 \pm 32.1(96.7-113.6)$ & $106.2 \pm 34.3(97.2-115.2)$ \\
\hline
\end{tabular}

Data are shown as means \pm SD $(95 \% \mathrm{CI})$

Table 3. Stepwise multiple linear regression analysis the SNIP values of females and males

\begin{tabular}{lcc}
\hline & Female & Male \\
\hline Prediction equation & $\mathrm{SNIP}=19.44+5.65 *$ BMI-2.06*body fat $\%$ & $\mathrm{SNIP}=21.10+1.24 * \mathrm{WT}$ \\
Mean SNIP $\left(\mathrm{cmH}_{2} \mathrm{O}\right)$ & 84.13 & 110.49 \\
$\mathrm{R}^{2}$ & 0.18 & 0.16 \\
$\mathrm{RSD}$ & 19.54 & 30.59 \\
$\mathrm{~B}$ & 19.44 & 21.10 \\
P value & $<0.01$ & $<0.01$ \\
Mean lower limit & 52.07 & 60.33 \\
\hline
\end{tabular}

BMI: body mass index; WT: body weight 
surement of SNIP has been underused in clinics because of a lack of standard data. A recent study reported that SNIP has as much predictive power for mortality in Chronic Obstructive Pulmonary Disease as hyperinflation determined the by IC/TLC ratio ${ }^{18)}$. That study showed that SNIP is not only an assessment tool but also has prognostic value.

According to our present results, SNIP is positively related to BMI and negatively related to body fat $\%$ in women, and positively related to weight in men. In their multiple linear regression models, Harik-Khan et al. ${ }^{19)}$ noted that MIP of women is negatively related to age and height, and positively related to weight, while MIP of men is positively related to weight and negatively related to age. We found SNIP relationships with weight and BMI but did not find age a significant factor (aging is discussed below).

The lower limits of normal for SNIP were defined by subtracting 1.64 times the residual SD from the predicted value in our regression model ${ }^{10)}$. According to this regression model, the lower limits of normal for SNIP were 49.3 $\mathrm{cmH}_{2} \mathrm{O}$ for females and $60.3 \mathrm{cmH}_{2} \mathrm{O}$ for males, meaning that $95 \%$ of healthy subjects have SNIP above the lower limits. Compared to previous data, our values are higher than those of Japanese $\left(28.8 \mathrm{cmH}_{2} \mathrm{O}\right.$ for females and 32.9 $\mathrm{cmH}_{2} \mathrm{O}$ for males) ${ }^{20)}$, and close to British values $(45.5 \mathrm{~cm}$ $\mathrm{H}_{2} \mathrm{O}$ for females and $50.1 \mathrm{cmH}_{2} \mathrm{O}$ for males) ${ }^{11)}$.

It is accepted that aging affects skeletal muscle strength, including inspiratory muscles ${ }^{21)}$. MIP is found to decrease as age increases ${ }^{19,22)}$, but conclusions regarding MIP cannot always be directly applied to SNIP. Our results show that age and SNIP are not related $(\mathrm{p}>0.05)$ in either gender. In contrast to recent studies, our result is consistent with the early classical work of Black and Hyatt ${ }^{23)}$, who reported that there was no significant regression of MIP with age in subjects younger than 55 yrs. We note that the age range covered in our present study was broader (18-69 yrs). Very few studies have specifically compared SNIP of different age groups, despite SNIP being reported to be negatively correlated with age in both genders ${ }^{24)}$, and men only ${ }^{12)}$.

There is significant interindividual variability in agerelated muscle strength decrease, and there is also a differential effect in men and women in age-related changes in upper and lower body strength ${ }^{25)}$. Research has shown that loss of muscle mass with aging is greater in the lower body ${ }^{26)}$, reflecting decreased activity of the lower extremity muscles with aging. The activity level of inspiratory muscles does not significantly decrease with age, so it is likely that inspiratory muscle strength does not significantly decrease either. We speculate that inspiratory muscle strength, since it is provided by core muscles, may not begin to substantially decline until late in life. These issues underline the need for continued research into the SNIP of all ages, cross-sectionally and longitudinally, especially that of the elderly.

The SNIP technique was developed in English-speaking countries, and normal values of SNIP estimated from reasonable sample sizes are only available for Caucasian adults $^{27)}$, children ${ }^{14)}$, and Japanese ${ }^{28)}$. Ethnicity may play a role in inspiratory strength ${ }^{7)}$. SNIP has only been studied in Taiwan with a small sample size $(\mathrm{n}=10)$ and local publica- tion $^{29)}$. The present study included a reasonable number of subjects with a range of ages and is therefore able to provide a reference value for SNIP. We believe these reference values will improve the utility of SNIP as a diagnostic or discriminatory tool for Taiwanese subjects. Furthermore, when standard procedures for testing SNIP and normal values are established, researchers and clinicians can begin to study how diseases affect SNIP longitudinally.

This is the first SNIP study in Taiwan that has included a reasonable number of subjects with a wide range of age. Measurement of SNIP provides an additional method for the assessment of inspiratory muscle strength. We conclude that 20 sniff maneuvers is the preferred number of trials, since the earlier recommendation of 10 maneuvers leads to underestimation; age does not affect SNIP in the age range we studied; and SNIP values of Taiwanese subjects are positively related with BMI in females and positively related with weight in males.

\section{ACKNOWLEDGEMENT}

Sources of financial support: partially supported by NSC 100-2410-H-320-016-MY3 through funding from National Science Council, Taiwan.

\section{REFERENCES}

1) Fitting JW: Volitional assessment of respiratory muscle strength. Monaldi Arch Chest Dis, 2012, 77: 19-22. [Medline]

2) van der Palen J, Rea TD, Manolio TA, et al.: Respiratory muscle strength and the risk of incident cardiovascular events. Thorax, 2004, 59: 10631067. [Medline] [CrossRef]

3) England R, Maddocks M, Manderson C, et al.: Factors influencing exercise performance in thoracic cancer. Respir Med, 2012, 106: 294-299. [Medline] [CrossRef]

4) American Thoracic Society/European Respiratory Society: ATS/ERS Statement on respiratory muscle testing. Am J Respir Crit Care Med, 2002, 166: 518-624. [Medline] [CrossRef]

5) Booth S, Moffat C, Burkin J, et al.: Nonpharmacological interventions for breathlessness. Curr Opin Support Palliat Care, 2011, 5: 77-86. [Medline] [CrossRef]

6) Terzi N, Corne F, Mouadil A, et al.: Mouth and nasal inspiratory pressure: learning effect and reproducibility in healthy adults. Respiration, 2010, 80: 379-386. [Medline] [CrossRef]

7) Chan CC, Cheong TH, Wang YT, et al.: Transdiaphragmatic pressure in young adult Singaporean subjects - normal values and a comparison between different respiratory manoeuvres. Aust N Z J Med, 1996, 26: 75-81. [Medline] [CrossRef]

8) Tantisuwat A, Thaveeratitham P: Effects of smoking on chest expansion, lung function, and respiratory muscle strength of youths. J Phys Ther Sci, 2014, 26: 167-170. [Medline] [CrossRef]

9) Huang $\mathrm{CH}$, Lee $\mathrm{CW}, \mathrm{Wu} \mathrm{YZ}$, et al.: Video instruction for measuring maximal inspiratory pressure. J Phys Ther Sci, 2012, 24: 1051-1054. [CrossRef]

10) Uldry C, Janssens JP, de Muralt B, et al.: Sniff nasal inspiratory pressure in patients with chronic obstructive pulmonary disease. Eur Respir J, 1997, 10: 1292-1296. [Medline] [CrossRef]

11) Steier J, Kaul S, Seymour J, et al.: The value of multiple tests of respiratory muscle strength. Thorax, 2007, 62: 975-980. [Medline] [CrossRef]

12) Kamide N, Ogino M, Sumida S, et al.: Relationships between dyspnea, respiratory muscle strength, and ventilatory failure in patients with amyotrophic lateral sclerosis. J Phys Ther Sci, 2007, 19: 223-225. [CrossRef]

13) Lofaso F, Nicot F, Lejaille M, et al.: Sniff nasal inspiratory pressure: what is the optimal number of sniffs? Eur Respir J, 2006, 27: 980-982. [Medline]

14) Stefanutti D, Fitting JW: Sniff nasal inspiratory pressure. Reference values in Caucasian children. Am J Respir Crit Care Med, 1999, 159: 107-111. [Medline] [CrossRef] 
15) Maillard JO, Burdet L, van Melle G, et al.: Reproducibility of twitch mouth pressure, sniff nasal inspiratory pressure, and maximal inspiratory pressure. Eur Respir J, 1998, 11: 901-905. [Medline] [CrossRef]

16) Bauer M, Czell D, Hartmann S, et al.: Limitations of sniff nasal pressure as an outcome measurement in amyotrophic lateral sclerosis patients in a clinical trial. Respiration, 2012, 84: 306-311. [Medline] [CrossRef]

17) Fauroux B, Aubertin G: Measurement of maximal pressures and the sniff manoeuvre in children. Paediatr Respir Rev, 2007, 8: 90-93. [Medline] [CrossRef]

18) Moore AJ, Soler RS, Cetti EJ, et al.: Sniff nasal inspiratory pressure versus IC/TLC ratio as predictors of mortality in COPD. Respir Med, 2010, 104: 1319-1325. [Medline] [CrossRef]

19) Harik-Khan RI, Wise RA, Fozard JL, The Baltimore Longitudinal Study of Aging: Determinants of maximal inspiratory pressure. Am J Respir Crit Care Med, 1998, 158: 1459-1464. [Medline] [CrossRef]

20) Gysels MH, Higginson IJ: The lived experience of breathlessness and its implications for care: a qualitative comparison in cancer, COPD, heart failure and MND. BMC Palliat Care, 2011, 10: 15. [Medline] [CrossRef]

21) Tolep K, Kelsen SG: Effect of aging on respiratory skeletal muscles. Clin Chest Med, 1993, 14: 363-378. [Medline]

22) Carpenter MA, Tockman MS, Hutchinson RG, et al.: Demographic and anthropometric correlates of maximum inspiratory pressure: The Athero- sclerosis Risk in Communities Study. Am J Respir Crit Care Med, 1999, 159: 415-422. [Medline] [CrossRef]

23) Black LF, Hyatt RE: Maximal respiratory pressures: normal values and relationship to age and sex. Am Rev Respir Dis, 1969, 99: 696-702. [Medline]

24) Wood H, Connors S, Dogan S, et al.: Individual experiences and impacts of a physiotherapist-led, non-pharmacological breathlessness programme for patients with intrathoracic malignancy: a qualitative study. Palliat Med, 2013, 27: 499-507. [Medline] [CrossRef]

25) Doherty TJ: Invited review: Aging and sarcopenia. J Appl Physiol 1985 , 2003, 95: 1717-1727. [Medline]

26) Janssen I, Heymsfield SB, Wang ZM, et al.: Skeletal muscle mass and distribution in 468 men and women aged 18-88 yr. J Appl Physiol 1985, 2000, 89: 81-88. [Medline]

27) Wood HSST. Individual experiences and impacts of a physiotherapist-led, non-pharmacological breathlessness programme for patients with intrathoracic malignancy: A qualitative study. 2013, 27: 499-507.

28) Kamide N, Ogino M, Yamashina N, et al.: Sniff nasal inspiratory pressure in healthy Japanese subjects: mean values and lower limits of normal. Respiration, 2009, 77: 58-62. [Medline] [CrossRef]

29) Chen TA, Chen WY, Wu YT: The reproducibility and validity of sniff test in healthy subjects. Formaosan J Phys Ther. 2005, 30: 332-338. 